Short Article

\title{
Venture Planning
}

\author{
Venice Mairya David
}

Professor and HOD, CHN Chirayu College of Nursing, Bhopal, Madhya Pradesh, India.

DOI: https://doi.org/10.24321/2348.2141.202003

\section{I $\quad \mathbf{N} \quad \mathbf{F} \quad \mathbf{O}$}

E-mail Id:

veniceanoop@gmail.com

Orcid Id:

https://orcid.org/0000-0002-1750-7735

How to cite this article:

David VM. Venture Planning. Trends Nurs Adm

Edu 2020; 9(2): 7-10.

Date of Submission: 2020-11-25

Date of Acceptance: 2020-12-22

\section{$\begin{array}{llllllll}\mathbf{A} & \mathbf{B} & \mathbf{S} & \mathbf{T} & \mathbf{R} & \mathbf{A} & \mathbf{C} & \mathbf{T}\end{array}$}

Venture management is a business management discipline that focuses on being both innovative and challenging in the realm of introducing what could be a completely new product or entering a promising newly emerging market. The discipline is focused on the skills, practices and technology required to manage the rapid growth of new business in highly dynamic environments. These environments are often characterized by rapid technology change.

Keywords: Venture Planning, Business Plan

\section{Introduction}

Venture Planning is a personal assessment of your feelings and the feasibility of venture. Venture Planning answers the question, should I be doing this and why? A type of written plan that is written by an entrepreneur as to how they will manage and direct their new business and attain specific business goals. This will help the new business owner in obtaining financial resources for attaining these goals. ${ }^{1}$

\section{Meaning}

Venture refers to a risky start-up or enterprise company. New ventures are a business plan that gives an opportunity or chance to set up a company/ business on the basis of innovative ideas. It is built upon customer driven ideas or technology.

\section{Venture Planning}

It is not a matter of writing a Business Plan. Venture Planning does not involve comprehensive endowment, source analysis, professional ideas, business structure or detailed market analysis. Venture Planning is the development of a comparative approach, various business models, usually by making a financial model to answer the following questions. ${ }^{1}$

- Which business idea produces the most sales, the best production, the highest profit and the lowest breakeven?

- What model requires less investment for entrepreneurs and others?

- Which concept needs equality as opposed to funding?

- Which produces the highest "Return on Investment" and the best money?

- Which model requires an entrepreneur to offer a small equity?

- $\quad$ Find and estimate the risks involved in making each model

\section{Venture Planning Stages}

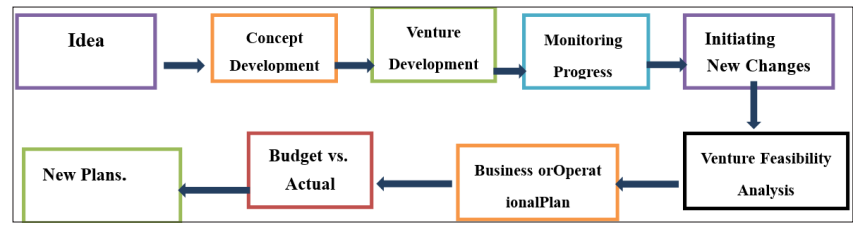

\section{Idea}

Business plans are an important test of clarity of thinking and clarity of the business. It is important that everyone has a clear understanding about the goal and objectives of organization new idea involves the process of creating realistic goals to be achieved. Thus it makes a business goal oriented. Today's world and markets are growing dynamic every day, in order to exceed competition, out of the box ideas are required to manage the functions of the enterprise. Venture an idea for a business that includes basic information such as the service or product, the target

Trends in Nursing Administration \& Education (ISSN: 2348-2141) 
demographic, and a unique selling proposition that gives a company an advantage over competitors.

\section{Concept Development}

Venture planning is the fundamental management function, which involves deciding beforehand, what is to be done, when is it to be done, how it is to be done and who is going to do it. It is an intellectual process which lays down organization's objectives and develops various courses of action, by which the organization can achieve those objectives. It chalks out exactly, how to attain a specific goal.

\section{Venture Development}

Venture development is the essence of HRM. It is a continuous activity which absolutely has no end. Initiating new ideas and challenges are important in achieving task of any organization. Competent technical skills are required to meet them. New strategies are required to overcome the storm created by the new trend. Managers must be shrewd enough to prove their dominance over rival.

\section{Monitoring Progress}

It refers to the evaluate the progress of the organization based on the objectives by evaluation reports before, during, and after the operational plan is implemented. Management has to plan for long-range and short-range future direction by looking ahead into the future, by estimating and evaluating the future behaviour of the relevant environment and by determining the enterprise's own desired role.

\section{Initiating New Changes}

Planning to initiation new changes means thinking about what is to be done, who is going to do it, and how and when he will do it. It also involves thinking about past events (retrospectively) and about future opportunities and impending threats (prospectively). Identify untoward conditions that could develop in achieving each objective. Decision-making is the key part of manager's activities. Decisions are important as they determine both managerial and organizational action.

\section{New Plans}

New Planning increases organizational performance and reduces the risk involved in modern business operations. Helps to coordinate within the organization. It helps to organize all available resources. It provides the right direction for the organization. It is important to maintain good control. It helps to achieve the goals of the organization. It motivates the staff of the organization.

\section{Business or Operational Plan}

It an outline of the future strategy will focus on for the future plans of an organization. It encourages managers' creativity and innovation. It also helps in decision-making. Operational plans are developed based on the long term objective and short term objectives.

\section{Budget vs Actual}

It refers to the process of comparing estimated results to actual results. Businesses study budget to actual to evaluate their performance, forecast future income and identify any operational centers that are performing differently than expected or gain profit and loss.

\section{Venture Feasibility Analysis}

It serves a critical function in independently evaluating a plan or planned course of action. Afeasibility analysis is to determine if it (1) is technically feasible, (2) is feasible within the estimated cost, and (3) will be profitable. ${ }^{2}$

\section{Keys of Good Venture Planning}

- Vision and mission of the organizaion or bussiness

- Competent policy maker

- Focus on one venture planning

- Discover the opportunity and how to use it

- Identify the demand of the venture

- Customers satisfaction

- Innovation and creative thinking

- Problem solving and decision making

- Helpful local environment.

- Neutral State and Federal Environment

- Fair decision

- Relevant Experience

- Cash flow audit

\section{Rising Venture Areas in Nursing that Needs Planning}

Often there is a crisis in the health care system in which nurses try to protect those present acclimatize models instead of accepting change. For good planning for successful businesses, managers should examine existing (traditional) facts, and analyze and agree with the changing nature of nursing. Some conventional facts are:

- Institutional-based care

- The process is well directed

- Process determined

- Based on mechanical and guide interventions

- Provided by the provider

- Supportive behavior/management

- Indicates phase time interventions

- Based on direct clinical relationships

\section{Application of Venture Planning in Nursing Practice}

According to Porter, O 'Grady (2003), the rising realities of nursing practice will be:

- Departure is based on multiple settings 
- Continuous effect

- Best practice

- Emphasis on technology and minimal non-invasive interventions

- User-driven

- Health system

- Preparing for early intervention

- Based on horizontal clinical relationships

\section{Venture Suggestions Checklist Suggestions}

An important tool to avoid any future problems for any companies

- Preventive strategies

- Emotional responses

- Continuing half-baked ideas

- Disaster consequences

- Stress management

- Interpersonal relationship

Exposing the Fear that Certain Facts may Damage what may seem like a Great Idea

It include 2 versions - Short version - Long version.

\section{Items in the Venture Proposal Checklist}

Framework of the Plan: The Framework Plan will be a high-level planning tool to coordinate, guide and inform the preparation and consideration of future, policies, rule and regulation is key aim planning to create diverse, compact and well-planned infrastructure, quality services that are affordable to all the individuals.

Appendices, Attachment etc.: Itinclude all pertinent supporting documents which provide detailed information aboutthe organization policies and business plan related documents. It allows the main body of the plan to read as a cohesive document that focuses on each aspect of your services.

Main Issues under the key Section: In any organization issues related to Uncertainty about the Financial management, Monitoring performance, Regulation and compliance, competencies and recruiting, Technology, Exploding data, customer service.

Work Program Assignments based on the Framework \& List: Improve working environment in the organization and motivated the staff for actively participating in fulfilling organization goal. It helpin determine the strength and weakness. Evaluation can help you identify areas for improvement and ultimately help you realize your goals more efficiently.

Key Sections in Logical Order: Based on the assessment organize or-priority theproblem-solving focuses on identifying needs in a failing community and creating external inputs to meet those problems.
Critiques from the Advisor: Critique is an analysis of a current problem or policyundertaking that focuses on its strengths and limitations. itis useful for taking best alternative for problem solving based on the finding and facts.

Summary \& Conclusion: To draw conclusions and make recommendations by the advisor based on finding and facts which are obtained at the end of program. Achieving the goal by highlighting the result of the products.

Evaluation Strategies: Itis the assessment process that provides executives and managers performance information about program, projects, and activities designed to meet business goals and objectives. ${ }^{3}$

\section{Resolution of Risk}

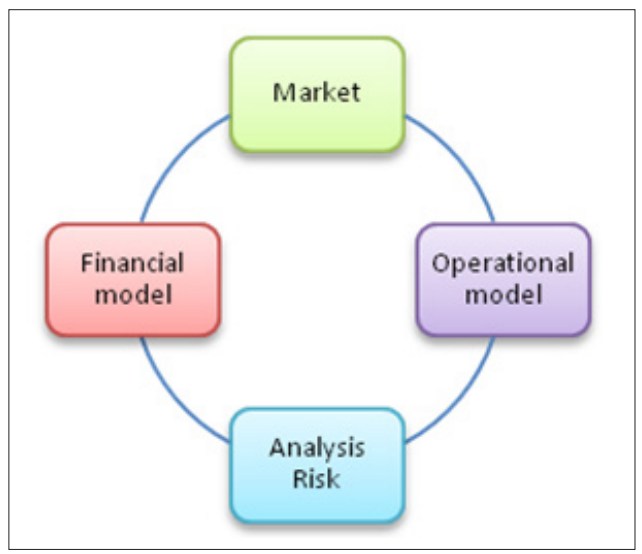

\section{Market Risks}

- Market Strength to Support the Venture

- Trends in the Market Structure

- Distribution of the market competition

\section{Operational Model}

- $\quad$ Problems related to delivering the quality products on customer

- Satisfaction Financial risk

Analysis Risk

- $\quad$ Developed new strategy based on the current needs of the consumers

\section{Financial Model}

- Resolution of Risk Market Analysis

- Revise Financial policy

- Cost analysis and cost Benefits

\section{Functions of Good Nurse Manager}

- $\quad$ The nurse administrator needs to know the plans and programs of the health facility,administratorand of other departments in which personnel contribute to the joint effort of, providing health care service 
- Involvement of all committees of the institution including those dealing with budgeting plannig credentialing auditing, utilization, infection control, patient care improvement, library or any other committee concerned with nursing activities and nursing personnel

- Develop a marketing operational plan based on the overall view of the agency problem and activities

- Marketing plan should include gathering and analysis of data related to product or service

- Operational planor stratergies find the possible strengths, weaknesses, problems and opptournities of the new bussiness

- Pre-planning or launching new business,organization prepare quality measure tool or performance evulation criteria

- Implementation policy or guidline for the recurtiment selction of the employee

- Competent personnel for analysis the compare expected results with actual

\section{Supportive Research}

Jianwen (Jon) Liao conducted a Panel Study of Entrepreneurial Dynamics (PSED) to explore whether engaging in business planning and the degree of planning formalization, combined with other activities, was more likely to result in the creation of new businesses. A review of longitudinal studies of emerging entrepreneur planning behaviors is provided and hypotheses are suggested about the relationship of pre-venture planning and planning formalization to success when starting new ventures. Findings of the study suggested that growing entrepreneurs who completed a business plan were 6 times more probable to start a business than individuals who were not able to plan any business plan. In addition, growing entrepreneurs who contact and participated in government-sponsored entrepreneurship programs were 5 times more possible to start a business than entrepreneurs who did not look for government assistance.

\section{Conflict of Interest: None}

\section{References}

1. Vati J. Principles \& practice of nursing management and administration, I ed., New Delhi, Jaypee Brothers Medical publishes (P) Ltd. 2013.

2. Deepak K, Chandran S, Kumar M. A comprehensive textbook on nursing management, I ed., Bangalore, Emmess Medical Publishers. 2013. 75-112.

3. Booyens WS. Dimensions of nursing management, Il ed., Cape Town, Zebra Publishers. 2007; 137- 139. 